\title{
A LA MEMORIA DE FERNANDO FUENZALIDA \\ (1936-2011)
}

Luis Alberto Suárez R.

Qué difícil. El Perú es un país de recuerdos múltiples. Puedes ser demonizado o subido a los altares. $\mathrm{Y}$ al mismo tiempo puede ser las dos cosas a la vez. Quisiera que se me recuerde como un profesor universitario de buena voluntad que quiso iluminar a sus contemporáneos. Y que tal vez logró algún éxito (Fernando Fuenzalida, Caretas 2009).

Estas palabras están dedicadas a la memoria de Fernando Fuenzalida Vollmar (Lima, 6 de enero de 1936-14 de abril de 2011). Sin duda alguna, fue uno de los antropólogos que junto a su generación dejaron una huella imborrable en la antropología peruana y las Ciencias Sociales en el Perú. Nadie podrá negar la importancia de trabajos como Estructuras tradicionales y economía de mercado (1969), Dominación y cambios en el Perú (1969) Lima IEP, Las Ciencias Sociales (1976), El Indio y el poder en el Perú 1970 Lima IEP, Tierra baldía. La crisis del consenso secular en la sociedad postmoderna (1995) Australis Editores, Lima 1995; y recientemente su compilación Agonía del Estado-Nación, editada por el Congreso de la República (2008).

Como muchos otros, lo conocí en las aulas sanmarquinas, durante la primera mitad de la década del 2000, sin duda alguna, fue para todos nosotros un mito viviente de las Ciencias Sociales, un mito que estaba plagado de historias y anécdotas, todas las cuales se juntaban como mosaico dándole forma a ese mito llamado Fernando Fuenzalida. Sin duda, él también alimentaba ese mito, se desplazaba por el aula con seguridad y aplomo, tomaba asiento cruzaba las piernas y recuerdo con claridad que una de las primeras frases que lo escuché decir fue: ¡Yo soy alumno de Max Gluckman, él a su vez tuvo como maestro a Radcliffe Brown, y él a su vez tuvo como maestro a Emile Durkheim! Ya esa sola frase nos dejó sin aliento, pasmados. 
Tuve la fortuna de llevar el curso de Antropología y Epistemología, este curso nos ofreció la posibilidad de conocer el mundo de Empedocles y los presocráticos, su discurso en el aula era didáctico, estimulante, su elocuencia provocaba empatía y despertaba fascinación, su discurso amalgamado por años de docencia, experiencia y lectura le daba la destreza para provocar un viaje en el tiempo y en el espacio, todos sin abruptos y con escala en diversos parajes; frecuentemente construía puentes y atajos, ahí donde el intelecto anquilosado no sospechaba, así, nos hablaba del paralelismo entre el mundo presocrático, el mundo de las vibraciones, que según él, fue similar al mundo andino, en tanto que las piedras y todo cuanto hay en la naturaleza vibra, tiene vida y está animado por fuerzas supremas. A través de su retórica, nos dio a conocer su pasión por las genealogías, nos ofreció una versión renovada de Aristóteles, explicándonos el concepto de physis y la generación de la naturaleza, el concepto de "materia" y su presencia en el pensamiento de Antoine-Laurent de Lavoisier, pasando por la compleja discusión de tomistas, neoaristotélicos versus neoplatónicos, para luego empalmar con la discusión sobre el sentido de la materia en el positivismo y en la emergencia del capitalismo. Era una clase que nos dejaban sin aliento, maravillados por las genealogías y los puentes tendidos entre espacios y tiempos inimaginables.

Sus clases salían de todos los esquemas clásicos de enseñanza, evadiendo responsabilidades como tomar examen, tomar controles, presentar trabajos, entre otros, solía fumar en clase, y si era interpelado para que dejara su cigarro, era capaz de sustentar por horas, cómo desde el hombre en las cavernas hemos desarrollado la resistencia para alternar nuestra vida con el humo, sustentación que dependiendo del ánimo de Fernando, podría tomar casi toda la sesión. Asignaba la saludable práctica de dejarnos a leer textos completos, para referirnos directamente a los autores. ¡Vayan a las fuentes!, repetía constantemente. En aquel curso nos dejó la tarea de leer a Claude Bernard, y su famoso texto "La medicina experimental", como punto de partida para interpretar a Durkheim y su organicismo. Algo que al principio parecía incompatible, pero convergente sin duda. Es cierto, no le gustaban las formas, dejaba un paquete de libros y jarrivedercl? Pero escucharlo y tomar café con él antes o después de las clases compensaba cualquier tipo rebeldía contra las formas.

También fue cierto que aquellos años debíamos de llamarlo, casi para convencerlo que debía de ir a San Marcos, hacerle recordar que ya habíamos leído los clásicos y esperábamos de él algunas sesiones más. Pero a veces era evasivo y el uso de su retórica fácilmente doblegaba nuestros argumentos. En aquellos años tenía una agenda muy recargada, enseñaba en ESAN, en la Académica de Diplomacia, en la Universidad del Pacífico, fue director del Centro de Altos Estudios Nacionales (CAEN) entre el 2004 y el 2005. Fue candidato al Parlamento Andino por el Partido Aprista Peruano en las elecciones generales del 2006. Fue Representante Parlamentario Electo de la República del Perú en condición de suplente del Parlamento Andino de la CAN. Su actividad académica siempre fue compatible con su labor en la polis.

A Fernando Fuenzalida siempre le gustaba estar a tono con los tiempos, adoraba su computadora Apple Macintosh, tenía más de un manual para programación, y se adelantó a la era del blog. En más de una clase, nos hacía una larga lista de autores 
y libros que debíamos leer si pretendíamos ser buenos antropólogos, pero advertía que no debíamos preocuparnos, al decir esto se volteaba y anotaba su página web en la pizarra http://ferfuvol.tripod.com, diciendo: "esta es mi página, se llama La Biblioteca del Diablo, con 300 títulos de diversos autores, clásicos y contemporáneos y en varios idiomas".

Sin duda alguna, su espíritu era incompatible con las formas académicas, los horarios y las reglas, por esa razón lo acompañé como su asistente en un curso que construimos juntos "Antropología y Economía", campo que se convirtió en foco de mi interés académico y luego fue objeto de mi tesis de licenciatura. Esta colaboración se interrumpió debido a algunos viajes, pero retomamos nuestra amistad en un momento muy intenso de su vida, su salud se había quebrantado y estaba en casa recuperándose. Una mañana llegué para pedir unas cartas y me quedé con él durante varios años. Desde ese momento, dejé de lado el mito Fernando Fuenzalida para conocer al hombre, al amigo, al caballero.

Mi trabajo con él se convirtió en una relación amical fructífera, visitaba interdiario su casa, gané su respeto, su confianza y su amistad. Sin duda alguna, aprendí más que en las aulas, pues logré conocer más sobre la vida y la importancia de saber levantarse a pesar de la adversidad, apostar por lo que amamos y valorar aquello en lo que creemos.

Aprendí no solo de aquel gran intelectual, sino del hombre con sus virtudes y defectos, con sus fracasos y sus victorias. Un hombre que desde nuestros pupitres sanmarquinos era evasivo, detractor de las reglas y normas, pero realmente descubrí un hombre de gran talento, que trabajó siempre, a pesar de sus dificultades físicas y su salud quebrantada, jamás dejó de leer y releer un manuscrito, su trabajo intelectual era su mundo, su tierra y su paraíso. Incluso colocó el trabajo por delante de las amistades; en una ocasión un amigo suyo había llegado de viaje, este llegó sin avisar, mientras que Fernando y yo leíamos en voz alta su texto, Fernando sintió que había sido bruscamente interrumpido y no dudo en despedirlo y pedir que vuelva otro día, me miró y me dijo con voz suave, ¡sigamos!

Conocí a un hombre amoroso con sus hijas, preocupado al extremo porque su entorno familiar mantenga relaciones cordiales y con cierto equilibrio. Nunca dudó en llamar a su fiel hija Rebeca y hacer todos los esfuerzos para explicarle las más audaces hipótesis intelectuales, y aunque no siempre tuvo éxito, esto no era un obstáculo para un hombre que puso por encima de todo el cariño y amor por unas hijas, que, él sabía, habían encontrado a su manera la forma de amarlo.

Sin dudas fue un hombre cariñoso y hospitalario. Siempre esperaba con el almuerzo una taza de café y otras atenciones. Esto lo atestigua también Hugo Neira, quien en su columna señaló “Generoso Fernando. En la casona del Paseo Colón dio instrucciones a la empleada para que cada noche preparara la cena para el amigo que llegaría a la hora que pudiera. Así, innumerables veces, tarde la noche, en la ancha mesa del comedor, la casa silenciosa, me esperaba un plato caliente, finamente envuelto en una servilleta limpia" (República 21 abril 2011).

La jornada en casa de Fernando Fuenzalida comenzaba no sin antes tener como fondo a Marlene Dietrich, Gertrude Lawrence, Andre Dassary o al genial 
compositor austriaco Leo Fall, aunque a veces me acusaba por mi obsesión a la zarzuela y cambiábamos de giro para escuchar Les Cinglés du Music Hall, un serie de canciones populares grabadas entre la primera y segunda guerra mundial. La música fue un bálsamo, o como él mismo decía, era el túnel del tiempo. Siempre teníamos que escuchar algunas canciones populares alemanas y mucha opereta porque le recordaban a su madre.

La revisión de la música, la contabilidad de los libros y el ordenar toda la biblioteca era la antesala de un trabajo minucioso, seguido por la lectura en voz alta de cada una de las páginas de aquel último libro — aún inédito— que ambos logramos suturar, pues de cuatro a cinco versiones que tuvo en mano, logramos tener uno solo, con más de trescientas cincuenta páginas, las cuales fueron leídas en voz alta pues ya su visión se había deteriorado. A pesar de esa limitación, era notable, pues sabía de memoria cada uno de los pies de página, los cuales crecían con atinadas observaciones, de lo contrario corríamos a la biblioteca para explorar las fuentes o me enviaba de regreso a leer un paquete de libros que luego discutíamos a media mañana.

\section{Herencia Intelectual}

Este notable intelectual dejó una serie de trabajos, ensayos, libros, manuscritos, de calidad y excepcionales por su contribución a las Ciencias Sociales, pero recordemos que la mayor parte del trabajo de Fernando estuvo en las aulas, ahí donde sus largos discursos, sus genealogías y sus puentes que unía el tiempo y el espacio. Su trabajo escrito es testigo de parte de ello, pero otra parte queda en la memoria de sus alumnos y amigos. En ese sentido, quisiera repasar algunas de estas valiosas contribuciones.

Él fue escuchado por todos, tirios y troyanos, por antropólogos y vasta infinidad de profesiones y disciplinas, pero no todos lograron comprender adecuadamente lo que quería decir, para unos tenía un discurso opaco, indescifrable, inaprensible, para otros era un excéntrico. En una ocasión dictó un seminario en el CAEM (hoy CAEN), el auditorio estaba compuesto por militares de altos rangos, mientras todos ellos, formalmente esperaban escuchar sobre globalización, Fernando Fuenzalida había decidido retomar a su estilo ese tema, los tenía encandilados con una disertación sobre el undécimo álbum de la banda británica de rock progresivo Pink Floyd The Wall (1979). Aquellos militares nunca olvidarán ese discurso; aunque como lo señala su amigo el Comandante(r) Julio Chamorro, llegó con retraso y preguntó "¿disculpen, de qué va el seminario?”.

Siempre escuché a otros decir que Fernando era excéntrico porque hablaba de duendes, hadas, elfos y otros. Sin embargo, mi trabajo con Fernando me permitió darme cuenta que todo esto era consistente, pues mientras que para aquellos eran solo "cuentos de hadas", para nosotros era un valioso material para avanzar hacia una visión comparada sobre un mundo en el cual los individuos y grupos sociales son parte de un mundo en el cual, el hombre es parte de una naturaleza mágica, mítica, y que esta de cierta forma en tensión con fuerzas naturales que están por encima de los hombres. En ese sentido, conocer sobre el mundo de los elfos y las hadas de la 
vieja Irlanda, sus peligros, riesgos, los rituales de reciprocidad para con ellos, es tan consistente como hablar sobre la mítica "gringa" y que al seguirla puedes terminar preso de su sortilegio, "el anciano" al cual siempre hay que alimentar y servir bien, por miedo al castigo de los apus. Siempre recomendó leer al famoso Robert Kirk, autor de La Comunidad Secreta, famoso demonólogo, folclorista, traductor y pastor protestante escocés; a Arrowsmith \& Moorse y su famoso Guia de campo de las hadasy demás elfos; a Edouard Brasey, con sus tratados sobre gnomos y elfos.

Fernando Fuenzalida, amaba las genealogías y siempre recomendó leer a Lucien Lévy-Bruhl Mentalité Primitive (1922), al filólogo e historiador francés Georges Dumézil, especialmente su tratado Mito y Epopeya (1977), este texto era la puerta de entrada a un mundo fascinante, el cual dominaba con arte y pasión, me refiero a los estudios sobre religión y antropología. Nos hablaba sobre el devenir de dioses indoeuropeos, ofreciéndonos una apasionada lectura del Mahäbhärata hasta los textos clásicos griegos y romanos. Sin dejar de contarnos las aventuras de Thor en la mitología nórdica y su relación con la Sociedad Secreta del Vril.

Nunca dejó de recomendar leer al historiador francés del siglo xIx, Numa Fustel de Coulanges, para hacernos recordar que todo hombre es rey y sacerdote, gracias a la Cité Antique (1864). Porque Fuenzalida, quien había crecido entre jesuitas en el centro de Lima, conocía los caminos de la fe cristiana, transitó por muchas formas de abrigar la fe, había leído textos mazdeistas, conocía muy bien los textos clásicos del Hinduismo, abrigó el budismo (fue amigo del Lama Ole Nydahl), conocía muy bien el sufismo. A esto se suma, una lectura acuciosa de textos de magia renacentista, textos iniciáticos desde la saga del Grial, pasando por Robert Fludd, Francis Bacon, Paracelso y otros alquimistas, asimismo místicos como Eckhart de Hochheim, Jakob Böhme, entre otros.

No fue un ecléctico, había logrado encontrar la síntesis, en otros términos, la esencia misma de la naturaleza mística; reparó con certeza que el núcleo de todo reside en la conexión, en la construcción de ese puente cósmico que une a los seres de la tierra con el universo, así, se convirtió en un apasionado de los libros de Tolkien, de símbolos como el Árbol de la Vida, y se replegó en sus últimos años en el estudio de la relación entre los mitos, las estrellas, las constelaciones y la cosmología. Por esa razón fue enfático en dejar como tarea el estudio de un libro esencial escrito por Giorgio de Santillana y Hertha von Dechend Hamlet's Mili (Godine, Boston, 1977), los autores analizan la relación entre el mito y patrones celestiales, sugiriendo que la mitología procede de una fuente estelar y desarrollan un modelo muy parecido al que se enseñaba a los iniciados en magia (Tres Mundos relacionados a tres niveles de una Esfera de Espacio). A esto se suman, los trabajos de Christopher Knight, Robert Lomas, Robert Temple, John Michell, Robert Schoch, entre otros.

Este último tópico constituía un fuerte interés, lo cual lo llevó a ser desde el inicio, parte de la Oficina de Investigación de Fenómenos Anómalos Aeroespaciales (OIFAA), de la Fuerza Aérea Peruana, incluso dio el discurso de inauguración de la OIFAA el 1 de noviembre, 2001. Fiel a su estilo, dijo que el estudio de los Fenómenos Anómalos Aeroespaciales representan desafíos que constituyen "un estímulo potente para una cuidadosa revisión de nuestros presupuestos epistemológicos, metodológicos 
y teóricos sobre la realidad y al mismo tiempo para la exploración imaginativa y creativa de nuevas alternativas tecnológicas que podrán eventualmente en un futuro no lejano ofrecer las soluciones a los problemas que agobian y ponen en peligro hoy la supervivencia misma de la humanidad" (Fuenzalida, 2001). Desde entonces, en sus clases, no solo hablaba de elfos, gnomos y hadas, ahora también incluiría breves disertaciones sobre los ovnis, pensados como parte del folclore urbano contemporáneo.

\section{Último texto: el reencuentro}

Fernando Fuenzalida fue un hombre que a pesar de las dificultades de su estado de salud en los últimos años, nunca abandonó el trabajo intelectual, gozaba de una memoria prodigiosa. Su último libro Orígenes del ocultismo contemporáneo. Rosacruces, masones y templarios — aún inédito- constituye su Magnum opus; pero al mismo tiempo es una suerte de cartografía a regiones más profundas de la psique al estilo de Jung.

Este último libro es complejo, de gran densidad histórica, fue compuesto tras una revisión exhaustiva. Este esfuerzo representa la posibilidad de ir más allá del racionalismo formal y sus caretas, lo que Sloterdijk llamó cinismo racionalista ilustrado. Así, logró entrecruzar los viejos temas del racionalismo e irracionalismo, y fue más allá de esta dicotomía, para reintegrarla en una mirada donde se entrecruzan relaciones de fuerzas ocultas a la mirada de cualquier espectador. Fuenzalida viajó a ese rincón de lo oculto, y analizó el devenir de las sociedades secretas, explorando ese mundillo de las sociétés de pensée del historiador Augustin Cochin, cómo se estructuraron, y cómo el proceso de su institucionalización dialogó con grupos de poder. Su estrategia de análisis histórico es rigurosa y se mueve con destreza en el terreno de la metafísica. Pero este libro ubica las coordenadas y plantea una estrategia metodológica para reintegrar las lógicas de poder, las dinámicas de fuerza y las aspiraciones de grupos secretos y metafísicos en la generación de estructuras y formaciones sociales y políticas.

Este libro puede ser interpretado desde otra perspectiva, ofrece pistas si se quiere para una iniciación, tiene una sólida imagen académica e historicista, pero es más que eso. Jaime de Althaus recordó que la exploración de Fuenzalida no solo fue teórica y académica, sino que fue vivencial, comprometida y nos recuerda que hacia fines de los setenta fundó una comunidad pentecostal en Cieneguilla denominada "Efratas" donde consiguió recuperar a muchos jóvenes de las garras de la droga, en esta etapa estuvo entregado al religare a la mística. Estoy convencido de que el último texto, de cierta forma lo reconcilia como este ser mágico, místico.

Sin duda fue maestro y guía. Nos enseñó a escuchar el llamado de una fuerza mayúscula, sellada por el compromiso, la confianza, y el deber. No solo nos invitó a disfrutar del cobijo, a los pies del frondoso árbol de la sabiduría; sino que nos extendió una invitación a tomar los instrumentos para salvaguardar y defender con honor y responsabilidad los valores que constituyen el círculo originario, constituido por la piedad, el amor, el deber, el afecto, y la rectitud.

En tiempo de la Grecia antigua, encender el fuego sagrado era un culto de la familia como adoración al antepasado divinizado, y cuyo altar de sacrificios era una 
tumba; y la familia eje fundamental de la estructura social, unida alrededor de un hogar, en ella, el altar y el fuego que siempre ardían de manera inextinguible. Cuando una familia hacía una invocación, primero se refería a la Divinidad del Hogar, y por ende, al fuego sagrado. La familia fue un Templo, y los padres, al mismo tiempo que sacerdotes, realizaban los sacrificios a los antepasados, y cuidaban del fuego sagrado. Todo era divino en la familia y los afectos mutuos estaban unidos por la piedad, por el amor, donde se conjugaban el sentimiento del deber, el afecto natural y la idea religiosa. El fuego sagrado en el altar, era al mismo tiempo fuego inmortal que subyace dentro del hombre y el ser invisible que mora en nosotros. Fernando Fuenzalida mantendrá siempre encendido el fuego en nuestros corazones, especialmente en aquellos que lo acompañamos en su camino; nos ofreció una invitación a mantener protegido el fuego y la llama del círculo original. Fundamento de toda solidaridad, y principio del amor como fuerza aglutinante de toda patria, de toda nación. 